J. Lake Sci.(湖泊科学), 2019, 31(2): 375-385

DOI 10. 18307/2019. 0207

(c) 2019 by Journal of Lake Sciences

\title{
水源水库季节性分层及悬浮物行为对铁锰迁移的影响——辽宁省 碧流河水库为例
}

\author{
姜 欣 ${ }^{1}$, 朱 林 $^{1}$, 许士国 ${ }^{1 * *}$, 谢在刚 ${ }^{2}$ \\ ( 1 : 大连理工大学建设工程学部水环境研究所, 大连 116024) \\ (2: 大连市碧流河水库管理局, 大连 116221)
}

\begin{abstract}
摘 要: 铁和镇是氧化还原敏感的元素, 水源水库热分层引起的底层水体缺氧造成了沉积物中铁和镇的释放, 对城市供 水造成了极大的影响. 以往鲜有悬浮物行为对铁和锰在水库水一沉积物界面迁移影响的研究, 于 2014 年 2 月- 2015 年 2 月对碧流河水库深水区的水、悬浮物以及沉积物铁和镇的垂向分布特征进行综合调查分析, 并进一步分析铁和锰的季节 性变化规律及悬浮物行为对其的影响. Spearman 相关分析结果表明铁浓度与总悬浮固体、总氮和总磷的相关性较大; 锰 浓度与总悬浮固体、溶解氧、 $\mathrm{pH}$ 和总氮的相关性较大. 进一步讨论分析表明碧流河水库的热分层、底层缺氧以及沉积物 再悬浮是影响铁和锰浓度的重要因素, 水库铁和锰的季节变化规律存在差异. 分层期溶解态的锰在底层累积, 平均浓度 达到 $0.18 \mathrm{mg} / \mathrm{L}$, 而沉积物中溶解态的铁释放很少. 混合期水库的中上层锰浓度升高, 达到了 $0.07 \mathrm{mg} / \mathrm{L}$. 沉积物的再悬浮 是水库底层水体中铁的主要来源, 底层颗粒态铁的平均浓度约为 $0.3 \mathrm{mg} / \mathrm{L}$. 絮凝的颗粒物以及其吸附的锰在水库长期悬 浮, 难以沉积到水库底部, 使得悬浮物中 $\mathrm{Mn}$ 的含量显著高于表层沉积物, 约为沉积物的 7 倍. 建议应在碧流河水库采用 分层取水、水库曝气以及联合供水等措施, 以减少铁和锰的浓度升高对供水产生的影响,保障大连市城市供水安全.
\end{abstract}

关键词: 铁; 锰; 悬浮物; 分层; 水源水库;碧流河水库

\section{Effects of seasonal stratification and suspended sediment behaviors on the mobilization of manganese and iron in a drinking water reservoir-A case of Biliuhe Reservoir, Liaoning Province}

\author{
JIANG Xin ${ }^{1}$, ZHU Lin $^{1}$, XU Shiguo ${ }^{1 * *}$ \& XIE Zaigang ${ }^{2}$ \\ (1: Institute of Water and Environmental Research, Faculty of Infrastructure Engineering, Dalian University of Technology, \\ Dalian 116024, P.R.China) \\ (2: Management Bureau of Biliuhe Reservoir, Dalian 116221, P.R.China)
}

Abstract: Iron and manganese are both redox-sensitive elements and important chemical indicators of drinking water quality. The anaerobic hypolimnion caused by thermal stratification results in the release of iron and manganese from sediments in water-supply reservoirs. The exceeding concentration of them may have a great impact on urban water supply. Little research has focused on the relationship between suspended sediment behaviors and the mobilization of iron and manganese in the water-sediment interface of reservoirs. To demonstrate the seasonal variation of iron and manganese and the influence of suspended matter on its behavior in the Biliuhe Reservoir, we comprehensively investigated and analyzed the vertical distribution characteristic of iron and manganese in water, suspended sediments, and sediments from February 2014 to February 2015. According to the results of Spearman correlation analysis, the concentration of iron is highly correlated with total suspended solids, total nitrogen, and total phosphorus, while, the concentration of manganese is significantly correlated with total suspended solids, dissolved oxygen, $\mathrm{pH}$ and total nitrogen. Further analysis results indicate that the thermal stratification, the anaerobic hypolimnion, and the resuspension of sediments significantly affect the concentration of iron and manganese in the Biliuhe Reservoir. The average dissolved manganese concentration accumulates

* 国家自然科学基金项目(51327004)资助. 2018-07-01 收稿;2018-08-29 收修改稿. 姜欣( 1988 ), 男,博士研究 生;E-mail:xinjiang@ mail.dlut.edu.cn.

** 通信作者; E-mail:sgxu@ dlut.edu.cn. 
on the bottom layer to $0.18 \mathrm{mg} / \mathrm{L}$ in the stratified season, while the dissolved iron releases very little from the sediment. The manganese concentration of the surface and middle layers increase to $0.07 \mathrm{mg} / \mathrm{L}$ in the mixing season. Because the average concentration of particulate iron in the bottom layer is approximately $0.3 \mathrm{mg} / \mathrm{L}$, the resuspension of sediments may be the main iron source in the bottom layer of the Biliuhe Reservoir. In addition, the flocculated particulate matter and its adsorbed manganese could stay in the reservoir for a long time, so that the content of manganese in the suspended matter is about 7 times higher than that in the surface sediments. Thus, to reduce the impact of elevated iron and manganese concentrations on water supply in the Biliuhe Reservoir, the most effective management practices focused on multi-level intake, hypolimnetic aeration, and amalgamated waterworks, which could ensure the safety of urban water supply in Dalian.

Keywords: Iron; manganese; suspended sediment; stratification; drinking water reservoir; Biliuhe Reservoir

铁和镇是人体正常生长代谢所必须的微量元素. 水中铁和锰的浓度过高会产生一些不利的影响. 铁和 锰会引起水色以及嗅味等感官问题 ${ }^{[1]}$, 同时锰是一种神经毒素, 摄人过多的锰会导致儿童学习障碍等神经 系统疾病 ${ }^{[2]}$. 我国《地表水环境质量标准》(GB 3838- 2002) 中规定集中式生活饮用水地表水源地中铁和锰 的标准限值分别为 0.3 和 $0.1 \mathrm{mg} / \mathrm{L}$. 为降低饮用水中铁和锰浓度, 在水处理中不得不增加氧化剂的投放量, 使得水处理成本增加. 随着低压膜分离技术在净水工艺中的应用, 预氧化过程中产生的二氧化镇导致的膜 污染成为限制该技术推广的重要原因 ${ }^{[3]}$. 此外, 在供水系统中的锰沉淀及其吸附有毒的金属离子容易再次 释放到水中,会对饮用水水质产生潜在的风险 ${ }^{[4]}$.

铁和锰的超标通常出现于以地下水和水库作为水源地的水源水中. 湖泊中的铁和锰在氧化还原界面和 沉积物一水界面的循环过程已经得到很好的阐述 ${ }^{[5]}$, 一般认为水库中的铁和镇的循环过程也相类似. 许多供 水水库都发现了底层水体铁或锰超标的现象, 比如英国的 Megget 水库 ${ }^{[6]}$, 澳大利亚的 Hinze 水库 ${ }^{[7]}$, 古巴的 Paso Bonito 水库 ${ }^{[8]}$, 贵州的阿哈水库 ${ }^{[9]}$, 青岛的王圈水库 ${ }^{[10]}$, 台州的长潭水库 ${ }^{[11]}$ 等, 引发供水危机, 使得在 净水处理中不得不强化铁和锰的去除工艺. 这些研究普遍认为水库的建设改变了河流原来的地貌及水力学 特征, 深水型水库在夏季容易产生水温分层现象, 有机质在水库深水区的沉积和降解会导致水库底层缺氧 环境的产生, 从而引起沉积物中铁和锰的释放, 导致上覆水中铁和锰的浓度升高, 这样使得采用底层取水的 供水方式的深水型水库存在较高的铁和锰超标的风险 ${ }^{[12]}$.

以上研究已经充分地意识到季节性的水库热分层对沉积物铁和锰释放的影响, 但是悬浮物对铁和锰在 水一沉积物界面间的迁移及水平迁移所起到作用关注较少. 悬浮物对污染物的吸附及伴随着其输移、絮凝、 沉降以及沉积物的再悬浮等行为对污染物在沉积物一水界面的迁移具有重要影响 ${ }^{[13-15]}$. 刘树元等 ${ }^{[11]}$ 认为人 库径流带来的颗粒态的铁锰只有在合适的还原条件下才能变成可溶态. Davison ${ }^{[16]}$ 在季节性缺氧的湖泊中 的研究中意识到水中铁锰的来源的差异, 沉积物释放是底层水体铁的主要来源, 而锰主要来自于沉降颗粒 的溶解. 为分析铁和锰季节性变化对水源水库供水的影响, 本文以大连碧流河水库为研究对象, 在分析水库 中铁和锰的浓度变化规律的基础上,探讨水库深水区悬浮物在铁和锰的迁移过程中的作用, 以期为碧流河 水库水质改善及供水安全保障提供新的解决思路.

\section{1 材料与方法}

\section{1 研究区域}

碧流河水库 $\left(39^{\circ} 49^{\prime} 14^{\prime \prime} \mathrm{N}, 122^{\circ} 29^{\prime} 30^{\prime \prime} \mathrm{E}\right.$ ) 位于辽宁省盖州、庄河和普兰店三市交界处, 是一座以城市供水 为主, 兼有防洪、发电、养鱼、灌溉、旅游等综合利用的大型水库. 水库流域控制面积 $2085 \mathrm{~km}^{2}$, 总库容 9.34 亿 $\mathrm{m}^{3}$, 兴利库容 6.44 亿 $\mathrm{m}^{3}$. 碧流河水库于 1984 年正式向大连供水, 到 1997 年 “引碧人连”三期工程竣工, 日最 大供水能力达到 120 万 $\mathrm{m}^{3}$,截止至 2016 年已累计向大连市供水近 70 亿 $\mathrm{m}^{3}$.

碧流河水库正常蓄水位 $69 \mathrm{~m}$, 取水口位于主坝上, 是水库向大连供水的咽喉, 输水洞进口底高程为 42.5 $\mathrm{m}$. 总体上看, 碧流河水质较好, 除总氮 ( TN) 浓度较高外,其他水质指标均优于地表水 III类标准.

\section{2 样品采集与分析方法}

在水库深水区设置 4 个采样点 S1 S4 进行采样, 如图 1 所示, 根据历史监测资料分析得到, 碧流河水库 分层水深在 $10 \sim 15 \mathrm{~m}$ 之间, 采样点水深均超过 $15 \mathrm{~m}$. 在 2014 年 2 月- 2015 年 2 月每个月进行取样, 明水期 
在由碧流河水库管理局提供的水质监测船甲板进行采样, 冰封期采用冰钻、镐头等破冰工具在冰面上进行 采样. 水温 $(\mathrm{T})$ 及深度 $(\mathrm{D})$ 数据采用水下温度传感器和压力传感器现场原位测定, 溶解氧 $(\mathrm{DO})$ 浓度采用多 参数水质仪 (Multi 340i, WTW, 德国) 测定, 水样采用卡盖式采水器 (FFWS, HYDRO-BIOS, 德国) 分表层、中 层和底层取样, $\mathrm{pH}$ 、 TN 及总磷 ( TP) 浓度采用国家标准方法进行测定.

取 $2 \mathrm{~L}$ 水样后用稀硝酸浸泡并冲洗干燥恒重后的 $0.7 \mu \mathrm{m}$ 玻璃纤维滤膜 ( GF/F, Whatman, 英国) 进行过 滤, 截留悬浮物的滤膜经称重后得到总悬浮物固体 ( TSS), 经 $\mathrm{HNO}_{3}-\mathrm{HClO}_{4}-\mathrm{HF}$ 消解后, 采用火焰原子吸收光 度计(TAS-990, 普析通用, 中国) 测定悬浮物中 $\mathrm{Fe}$ 和 $\mathrm{Mn}$ 含量 $(\mathrm{mg} / \mathrm{g})$, 再乘以 TSS $(\mathrm{g} / \mathrm{L})$ 后得到颗粒态铁 $(\mathrm{PFe})$ 和颗粒态锰 $(\mathrm{PMn})$ 浓度 $(\mathrm{mg} / \mathrm{L})$, 水中溶解态铁 $(\mathrm{DFe})$ 和溶解态锰 $(\mathrm{DMn})$ 浓度 $(\mathrm{mg} / \mathrm{L})$ 采用火焰原子 吸收法测定过滤样本, 总铁 $(\mathrm{TFe})=\mathrm{PFe}+\mathrm{DFe}$, 总锰 $(\mathrm{TMn})=\mathrm{PMn}+\mathrm{DMn}$. 沉积物物样品在 2014 年 8 月和 9 月 使用抓斗式采泥器 (Van Veen, KC-Denmark, 丹麦) 采集表层 $0 \sim 2 \mathrm{~cm}$ 沉积物, 风干过篮样品经 $\mathrm{HNO}_{3}-\mathrm{HClO}_{4}$ $\mathrm{HF}$ 消解后, 采用火焰原子吸收法测定沉积物中 $\mathrm{Fe}$ 和 Mn 含量.

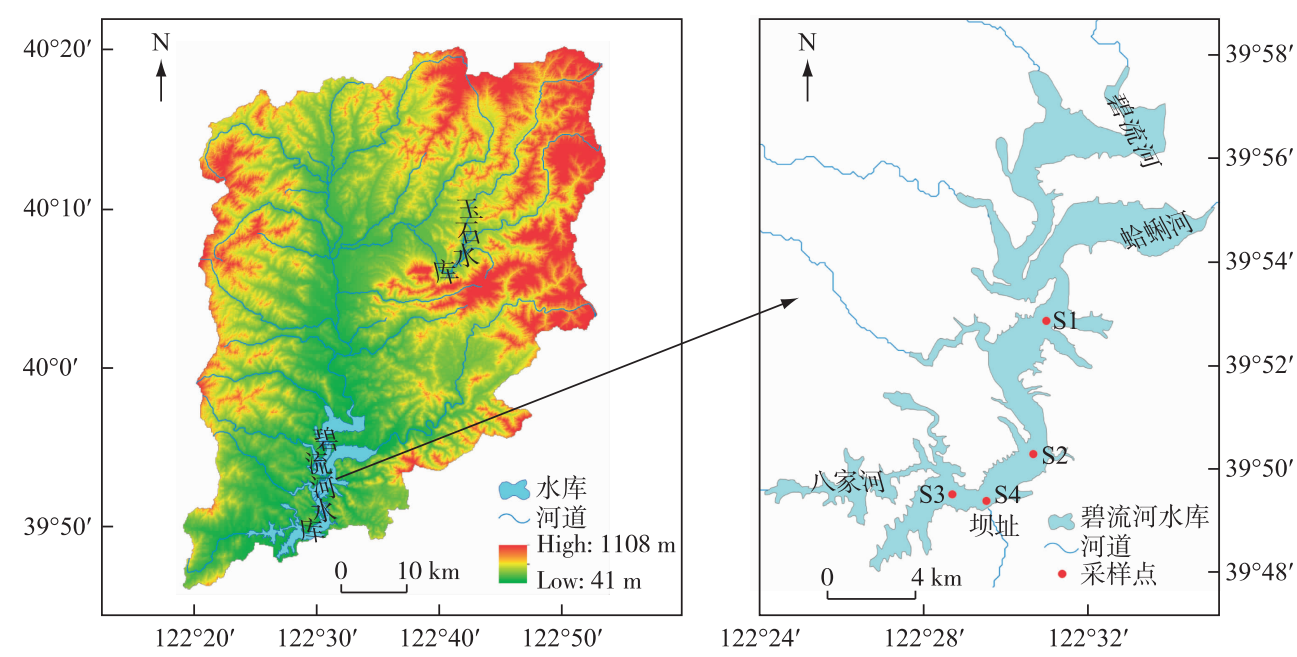

图 1 碧流河水库的地理位置及采样点分布

Fig.1 The location of the Biliuhe Reservoir and its sampling sites

\section{3 数据处理}

按照垂向上不同深度分为表层、中层和底层,按照碧流河水库水温变化特征分为冰封期、混合期和冰封 期. 后文对湖泊不同水深分层及不同温度时期的划分, 均有进一步详细说明. TFe、TMn、PFe、PMn、DFe 和 DMn 浓度分别进行方差分析 (ANOVA, S-N-K), 显著性水平为 0.05 . Spearman 相关性分析和主成分分析 (PCA) 采用 SPSS 23.0 软件进行计算, 水温及溶解氧的剖面图采用 Surfer 14.0 软件进行绘制, 条形图和箱式 图采用 Origin 2016 软件绘制.

\section{2 结果与分析}

\section{1 水温与溶解氧季节性分层特征}

碧流河水库坝前水深随着碧流河水库的水位不断变化, 从图 2 可以看出, 在 2014 年 2 月-2015 年 2 月 碧流河水库坝前水温垂向的季节性变化特征明显, 属于典型的双季对流混合型, 在 12 月下旬一 2 月为冰封 期, 6-9 月为稳定分层期, 3-5 月和 10- 12 月中旬为两次混合期. 在冰封条件下,冰盖厚度在 $20 \sim 30 \mathrm{~cm}$ 左 右, 表层水温在 $0^{\circ} \mathrm{C}$ 左右, 底层水温稳定在 $4^{\circ} \mathrm{C}$ 左右. 在第一次混合表层水与底层水温差不大, 表层水温逐渐 升高到 $10^{\circ} \mathrm{C}$ 以上, 而底层水温缓慢上升. 在温度分层期, 表层水温随着气温的升高迅速增加, 而底层水温增 加缓慢, 水温在 $8 \sim 12^{\circ} \mathrm{C}$ 之间逐步上升, 存在明显的温跃层, 温跃层深度同时呈现逐步下移趋势. 在第二次混 合期, 气温逐渐降低, 表层水温逐渐回落, 11 月水温逐步回落到 $10^{\circ} \mathrm{C}$ 左右, 表层水温和底层水温混合均匀. 
从图 2 中可以看出,碧流河水库中坝前 DO 浓度垂向的季节性变化特征同样也很明显,同水库的水温分 层具有高度的一致性. 当水库在 6 月之后出现水温分层现象, 上下层水体得不到充分交换, 随着底层水体和 沉积物中有机物降解对 DO 消耗, 底层水体 DO 浓度逐渐降低到 $2 \mathrm{mg} / \mathrm{L}$ 以下. 到 9 月下旬后, 水温分层稳定 性降低, 上下层水体能够充分混合, 底层水体的 DO 浓度会逐渐上升. 甚至在冰封期, 碧流河水库底层的 DO 浓度仍然很高, 接近甚至超过饱和 DO 浓度.

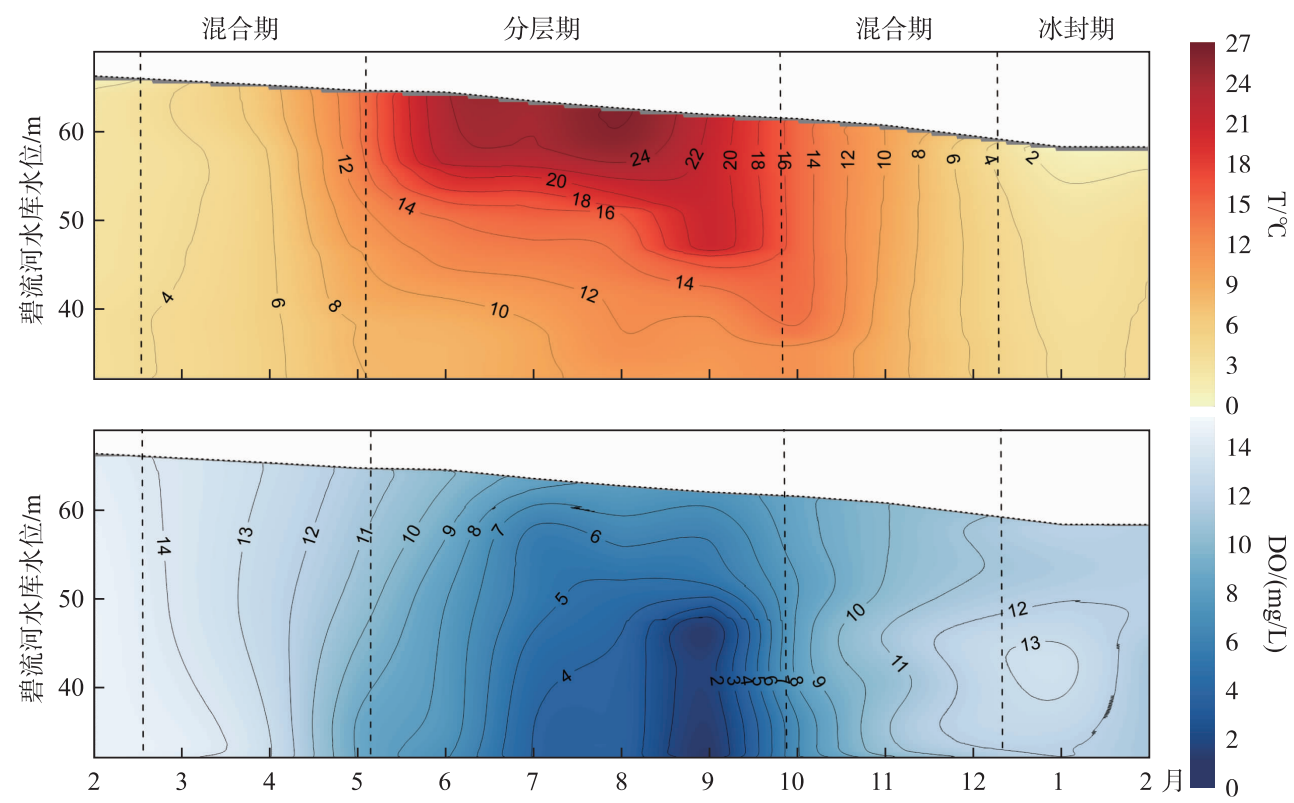

图 2 碧流河水库坝前水温及溶解氧季节性变化剖面图 (S4)

Fig. 2 The seasonal vertical profiles of water temperature and dissolved oxygen nearby the Dam of Biliuhe Reservoir ( S4)

\subsection{Fe、Mn 浓度的垂向分布及季节性变化特征}

从图 3 可以看出, 碧流河水库深水区 $\mathrm{Fe} 、 \mathrm{Mn}$ 浓度分布具有明显的垂向差异和季节性变化特征. 方差分 析结果表明, 碧流河水库水体 $\mathrm{Fe} 、 \mathrm{Mn}$ 浓度分层差异具有统计显著性, 底层水体 $\mathrm{TFe} 、 \mathrm{TMn} 、 \mathrm{PFe} 、 \mathrm{PMn} 、 \mathrm{DFe}$ 和 $\mathrm{DMn}$ 浓度均高于表层和中层. TFe 和 $\mathrm{PFe}$ 浓度的季节性差异不具有统计显著性, 分层期 $\mathrm{DFe}$ 浓度显著高于 冰封期, 而混合期 DFe 浓度与分层期和冰封期差异不具有统计显著性; 分层期 TMn 浓度高于冰封期, 而混合 期 TMn 浓度与分层期和冰封期差异不具有统计显著性, DMn 浓度在分层期高于混合期和冰封期, 冰封期 PMn 浓度低于混合期和分层期.

碧流河水库深水区表层和中层 $\mathrm{TFe}$ 平均浓度为 $0.10 \mathrm{mg} / \mathrm{L}, \mathrm{DFe}$ 和 $\mathrm{PFe}$ 平均浓度分别为 0.03 和 0.07 $\mathrm{mg} / \mathrm{L}$, 主要以 $\mathrm{PFe}$ 为主, 占 $70 \%$ 以上; 在混合期, 表层和中层的 $\mathrm{PFe}$ 平均浓度增加到 $0.12 \mathrm{mg} / \mathrm{L}$. 底层 $\mathrm{TFe}$ 平 均浓度升高, 达到 $0.35 \mathrm{mg} / \mathrm{L}$, 为表层和中层的 3.5 倍; 底层水体 $\mathrm{DFe}$ 平均浓度在冰封期和混合期为 $0.04 \mathrm{mg} / \mathrm{L}$, 在分层期稍有升高, 达到 $0.08 \mathrm{mg} / \mathrm{L}$; 虽然底层水体仍以 $\mathrm{PFe}$ 为主, 平均浓度为 $0.29 \mathrm{mg} / \mathrm{L}$, 但所占比例降到 了 $60 \%$ 左右.

碧流河水库深水区冰封期水体中 $\mathrm{Mn}$ 浓度较低, 表层和中层的 $\mathrm{TMn}$ 平均浓度小于 $0.01 \mathrm{mg} / \mathrm{L}$, 底层稍有 升高, 为 $0.04 \mathrm{mg} / \mathrm{L}$; 混合期水体中 $\mathrm{Mn}$ 浓度较高, 各层平均浓度差异不大, 约为 $0.07 \mathrm{mg} / \mathrm{L}$, 主要以 $\mathrm{PMn}$ 为 主, 约占 $73 \%$ 左右; 分层期水体中 $\mathrm{Mn}$ 浓度随着水深的增加逐渐增加, 表层 $\mathrm{TMn}$ 平均浓度小于 $0.01 \mathrm{mg} / \mathrm{L}$, 中 层为 $0.04 \mathrm{mg} / \mathrm{L}$, 底层达到了 $0.29 \mathrm{mg} / \mathrm{L}$, 其中 $\mathrm{DMn}$ 平均浓度显著升高, 达到 $0.18 \mathrm{mg} / \mathrm{L}$, 超出地表水源地标准 限值, PMn 所占比例也降到了 $46 \%$ 左右. 

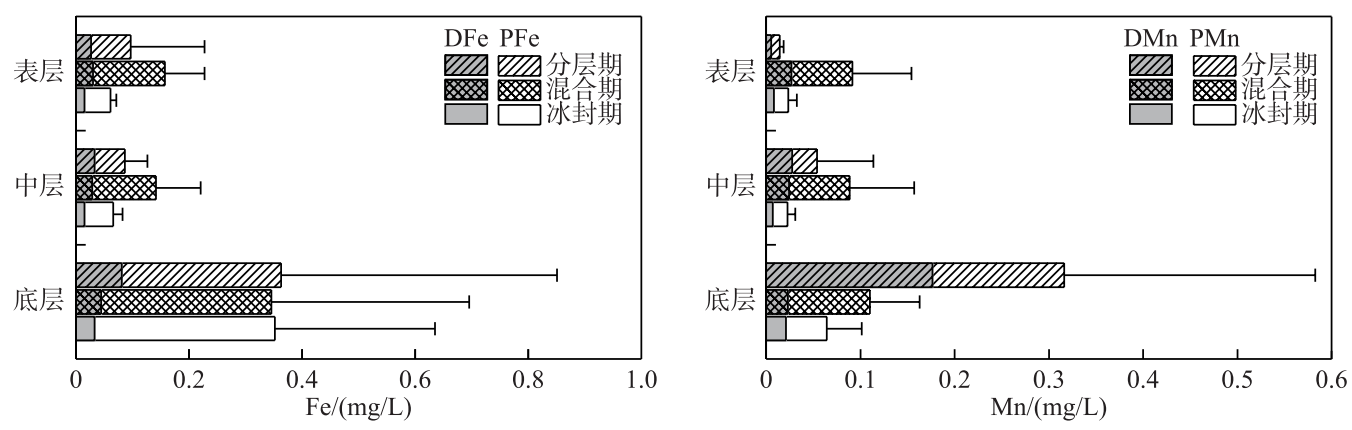

图 3 碧流河水库不同时期铁和锰浓度垂向分布特征

Fig. 3 The vertical distribution of the Fe and Mn concentrations of the Biliuhe Reservoir in different periods

\subsection{Fe、Mn 浓度与其他环境因子之间的关系}

TFe 、TMn、DFe、DMn、PFe 和 PMn 与 T、pH、DO、TP、TN、COD 和 TSS 的相关关系如表 1 所示, 结果表明, $\mathrm{TFe} 、 \mathrm{PFe}$ 与 $\mathrm{TSS}$ 呈极强的正相关性 $(r=0.763$ 和 0.737$), \mathrm{TFe} 、 \mathrm{PFe}$ 与 $\mathrm{TN}$ 呈显著的负相关性, 与 $\mathrm{TP}$ 呈正相关 性. DFe 与 TSS 呈显著的正相关性, 与 DO 呈显著的负相关性,与 T 呈正相关性, 与 $\mathrm{pH}$ 呈负相关性.

TMn、PMn 与 TSS 呈显著的正相关性, 与 $\mathrm{pH}$ 、TN 呈负相关性. TMn 和 DMn 与 DO 呈显著的负相关性. $\mathrm{DMn}$ 与 TSS 呈显著的正相关性,与 $\mathrm{pH}$ 呈显著的负相关性, 与 COD 呈负相关性.

表 $1 \mathrm{Fe} 、 \mathrm{Mn}$ 浓度与环境因子之间的 Spearman 相关性分析

Tab.1 Spearman correlation analysis between Fe and Mn concentrations and environmental variables

\begin{tabular}{cccccccc}
\hline 相关性 & $\mathrm{T}$ & $\mathrm{pH}$ & $\mathrm{DO}$ & $\mathrm{TN}$ & $\mathrm{TP}$ & $\mathrm{COD}$ & $\mathrm{TSS}$ \\
\hline $\mathrm{TFe}$ & -0.069 & -0.015 & -0.057 & $-0.248^{*}$ & $0.232^{*}$ & 0.091 & $0.763^{* *}$ \\
$\mathrm{PFe}$ & -0.151 & 0.041 & 0.076 & $-0.280^{* *}$ & $0.237^{*}$ & 0.113 & $0.737^{* *}$ \\
$\mathrm{DFe}$ & $0.207^{*}$ & $-0.217^{*}$ & $-0.388^{* *}$ & 0.027 & 0.144 & -0.096 & $0.513^{* * *}$ \\
$\mathrm{TMn}$ & -0.112 & $-0.251^{*}$ & $-0.321^{* *}$ & $-0.213^{*}$ & 0.169 & -0.138 & $0.571^{* *}$ \\
$\mathrm{PMn}$ & -0.186 & $-0.213^{*}$ & $-0.195^{*}$ & $-0.235^{*}$ & 0.092 & -0.120 & $0.595^{* *}$ \\
$\mathrm{DMn}$ & -0.157 & $-0.317^{* *}$ & $-0.319^{* *}$ & $-0.242^{*}$ & 0.128 & $-0.194^{*}$ & $0.400^{* *}$ \\
\hline
\end{tabular}

*表示在 0.05 水平 (双尾) 相关性显著; $* *$ 表示在 0.01 水平 (双尾) 相关性显著.

从相关性分析结果来看, Fe 浓度与 TSS、TN 和 TP 的相关性较大; Mn 浓度与 TSS、DO、pH 和 TN 的相关 性较大. TSS 对 Fe 浓度的影响要比对 Mn 浓度的影响大, 主要由于 TFe 中 PFe 所占比例较大 $(>70 \%)$. 由于 $\mathrm{TN}$ 主要由 $\mathrm{NO}_{3}^{-}$组成, 高浓度的 $\mathrm{NO}_{3}^{-}$会影响水体的氧化还原条件, 可能影响沉积物中 $\mathrm{Fe}$ 和 $\mathrm{Mn}$ 的释放. 悬浮 颗粒中铁铝氧化物容易与磷酸根离子交换吸附, 因此 Fe 浓度与 TP 浓度有显著的相关性. $\mathrm{pH}$ 和 DO 对 DFe 和 DMn 浓度的影响要比对 PFe 和 PMn 的影响大, 在 $\mathrm{pH}$ 和 $\mathrm{DO}$ 浓度较低的情况下沉积物中的 $\mathrm{Fe}$ 和 $\mathrm{Mn}$ 会释 放出来从而导致 DFe 和 DMn 浓度的升高. T 和 COD 对 Fe、Mn 浓度的影响不大.

采用 PCA 方法对 TFe、TMn、DFe、DMn、PFe 和 PMn 与 T、pH、DO、TP、TN、COD 和 TSS 的关系进行分析, 共提取出 4 个主成分, 贡献率分别为 $37.5 \% 、 17.5 \% 、 12.1$ 和 $9.4 \%$, 图 4 为各主成分的载荷图. 分析结果表明 在 4 个主成分中 $\mathrm{TSS}$ 与 $\mathrm{PFe}$ 和 TFe 的相关性都较大; PC1 与 $\mathrm{T} 、 \mathrm{COD} 、 \mathrm{TN}$ 和 $\mathrm{pH}$ 相关性不大, 与 $\mathrm{DO}$ 呈负相 关, 与 $\mathrm{Fe} 、 \mathrm{Mn} 、 \mathrm{TSS}$ 和 TP 等均呈正相关; PC2 与 DO 、 pH、COD、TSS、TFe、PFe 和 PMn 等均呈正相关, 与 DMn、 $\mathrm{TN} 、 \mathrm{TMn} 、 \mathrm{DFe} 、 \mathrm{TP}$ 和 T 等均呈负相关, 表征了溶解态和颗粒态 $\mathrm{Fe} 、 \mathrm{Mn}$ 的差异; PC3 与 $\mathrm{T}$ 和 $\mathrm{pH}$ 均呈正相关, 而 与 $\mathrm{Fe} 、 \mathrm{Mn}$ 浓度相关不大; PC4 与 DO、DMn、DFe、TP 和 COD 等均呈正相关, 与 T 和 TSS 等均呈负相关.

\section{4 悬浮物与表层沉积物中 $\mathrm{Fe}, \mathrm{Mn}$ 含量}

悬浮物中 $\mathrm{Fe}$ 平均含量为 $25.2 \mathrm{mg} / \mathrm{g}$, 表层沉积物中为 $33.7 \mathrm{mg} / \mathrm{g}$, 表层沉积物中 $\mathrm{Fe}$ 含量约为悬浮物的 1.3 倍; 而悬浮物中 $\mathrm{Mn}$ 平均含量为 $12.3 \mathrm{mg} / \mathrm{g}$, 表层沉积物中为 $1.74 \mathrm{mg} / \mathrm{g}$, 悬浮物中 $\mathrm{Mn}$ 含量约为沉积物的 7 

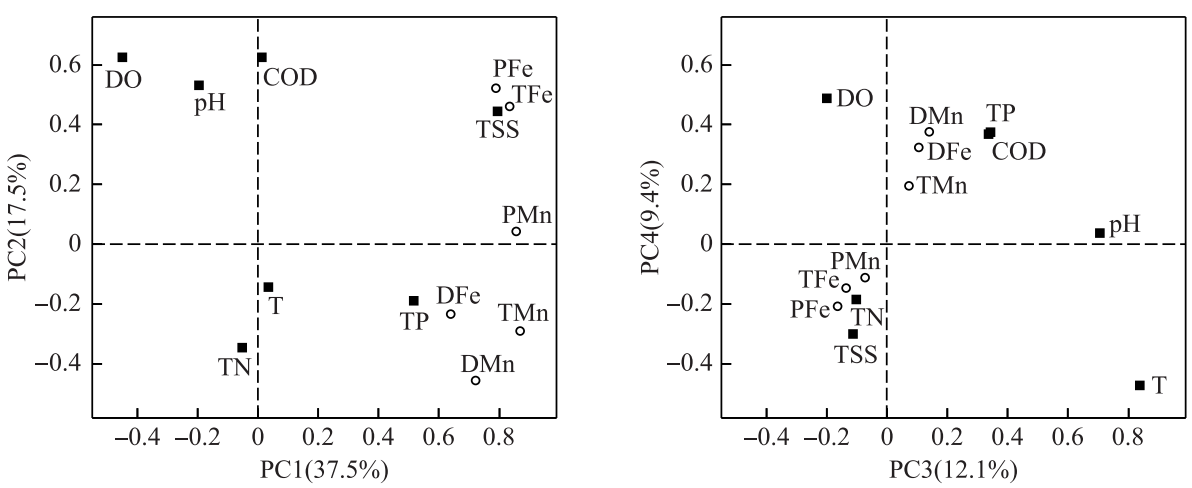

图 4 碧流河水库水质指标 PCA 载荷图

Fig.4 The PCA loading plot of water quality parameters in the Biliuhe Reservoir

倍, 说明与表层沉积物相比,悬浮物对 Mn 的富集能力要大很多(图 5).

方差分析结果表明,碧流河水库中悬浮物中 $\mathrm{Fe} 、 \mathrm{Mn}$ 含量具有明显的季节性变化特征. 悬浮物中 $\mathrm{Fe}$ 平均 含量混合期最高, 为 $35.0 \mathrm{mg} / \mathrm{g}$, 冰封期次之, 为 $29.0 \mathrm{mg} / \mathrm{g}$, 分层期最低, 为 $18.4 \mathrm{mg} / \mathrm{g}$; 而在垂向的差异不具 有统计显著性, 表层和中层稍低 (为 $23.7 \mathrm{mg} / \mathrm{g}$ ), 底层稍高 (为 $28.1 \mathrm{mg} / \mathrm{g}$ ). 悬浮物中 $\mathrm{Mn}$ 的平均含量在混合 期最高, 冰封期和分层期次之; 在垂向上底层最高, 中层次之, 表层最低. 而双因素方差分析结果表明, 在不 同水深和不同季节的双重影响下的悬浮物锰含量差异具有统计显著性, 在混合期和冰封期各层悬浮物中 $\mathrm{Mn}$ 平均含量并无显著差异, 分别为 17.0 和 $7.86 \mathrm{mg} / \mathrm{g}$, 而在分层期底层悬浮物中 $\mathrm{Mn}$ 平均含量最高 (为 22.1 $\mathrm{mg} / \mathrm{g}$ ), 中层次之 (为 $9.05 \mathrm{mg} / \mathrm{g}$ ), 表层最低 (为 $3.00 \mathrm{mg} / \mathrm{g}$ ).
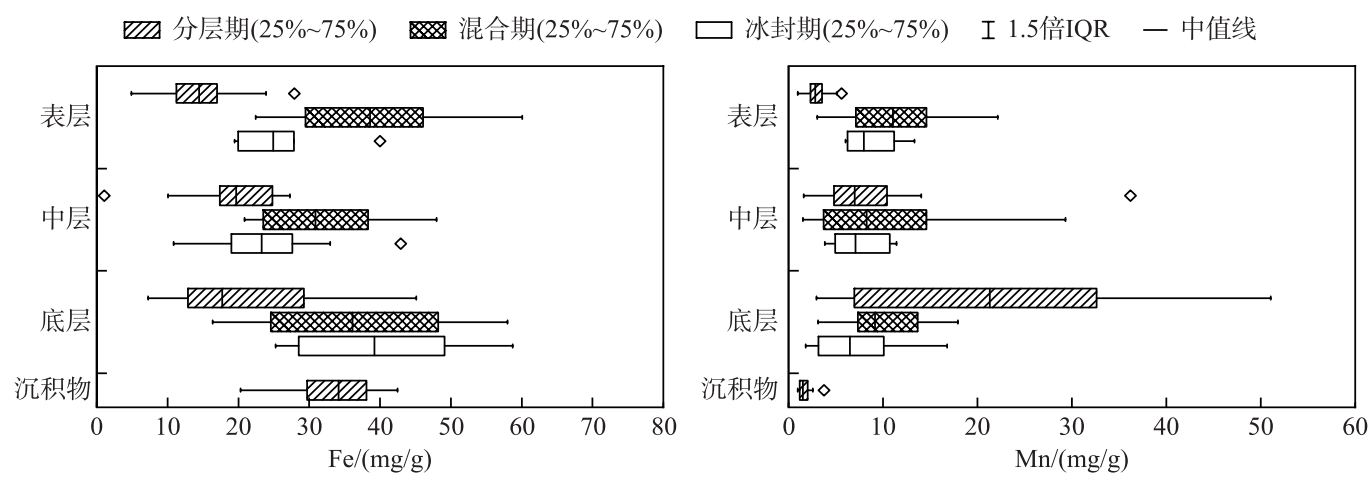

图 5 碧流河水库深水区悬浮物及表层沉积物 $(0 \sim 2 \mathrm{~cm})$ 中铁和锰的含量比较

Fig.5 The iron and manganese contents in the suspended and surface sediment $(0-2 \mathrm{~cm})$ in the deep area of the Biliuhe Reservoir

\section{3 讨论}

\section{1 考虑悬浮物行为的季节性铁锰迁移规律}

3.1.1 分层期 碧流河水库在 6-9 月为稳定的分层期, 上下层水体的温差导致水库垂向混合不均匀,随着底 层水温的逐渐升高, 底层水体及表层沉积物耗氧速率增大, 在分层期底层水体产生缺氧环境 $(\mathrm{DO}<3 \mathrm{mg} / \mathrm{L})$. $\mathrm{Fe} 、 \mathrm{Mn}$ 是氧化还原敏感性的元素, 在还原条件下, $\mathrm{Fe} 、 \mathrm{Mn}$ 以溶解态的 $\mathrm{Fe}^{2+}$ 和 $\mathrm{Mn}^{2+}$ 存在. 在分层期底层缺氧环 境中, 沉积物中 $\mathrm{Fe} 、 \mathrm{Mn}$ 氧化物的溶解并向水体中释放, 导致了分层期底层水体中 DFe、DMn 浓度的增加, 这 与其他水库观测的结果类似, 但是由于 $\mathrm{Mn}$ 氧化物能高于 $\mathrm{Fe}$ 氧化物的氧化还原电位下被还原 ${ }^{[17]}$, 而且碧流 
河水库水体中高浓度的 $\mathrm{NO}_{3}^{-}(>2 \mathrm{mg} / \mathrm{L})$ 使得底层氧化还原电位维持在 $110 \sim 150 \mathrm{mV}$ 之间, 因此只有少量的 $\mathrm{Fe}^{2+}$ 释放到水中,分层期沉积物中 Mn 要更容易释放, DMn 浓度要高于 DFe 浓度 (图 3).

另外,在向上扩散过程中 $\mathrm{Fe}^{2+}$ 和 $\mathrm{Mn}^{2+}$ 被氧化为 $\mathrm{Fe}(\mathrm{III})$ 和 $\mathrm{Mn}(\mathrm{III}, \mathrm{IV})^{[5]}$, Estweit Water 湖下层中研究表 明 DMn 氧化过程相当缓慢, 完全氧化需要 10 天, 而溶解态的 $\mathrm{Fe}$ (II) 氧化只需要 $5 \mathrm{~h}^{[18]}$, 因此 DFe 会被迅速 氧化沉淀到水库底部, 而 DMn 可以继续向上扩散到水库的温跃层, 进而和悬浮颗粒结合, 因此在分层期悬浮 物中 $\mathrm{Fe}$ 含量要远低于沉积物 (图 5). 由于温跃层水体垂向涡动扩散系数降低 ${ }^{[19]}$, 阻隔了 $\mathrm{DMn}$ 继续向上扩 散, DMn 在温跃层逐渐被氧化为粒径较大的 $\mathrm{Mn}(\mathrm{III}, \mathrm{IV})$ 的絮凝体后沉降 ${ }^{[20]}$. 因此在分层期水库中层和底层 悬浮物中的 Mn 含量要远高于表层悬浮物 (3 7 倍) 和沉积物 (5 13 倍) (图 5). 此外, 在 Carvins Cove 水库 中的研究表明, 水库上游深水区底层水一沉积物界面释放的 DMn 进人上覆水体, 通过水流输送, 成为下游底 层水体 DMn 的主要来源 ${ }^{[21]}$. 碧流河水库在 S1 (图 1) 观测到底层 DMn 浓度要高于下游 S2 和 S4, 可以推测 $\mathrm{S} 1$ 沉积物释放的 DMn 通过水流的输送引起坝前取水口 DMn 浓度的升高.

因此如图 6 所示, 在分层期水库热分层引起的底层缺氧层的产生, 导致沉积物中 $\mathrm{Mn}(\mathrm{II})$ 的大量释放, 通 过向上扩散和水流的输送而引起输水口附近 DMn 浓度的升高, 因此城市供水主要受到底层高浓度 DMn 的 影响.

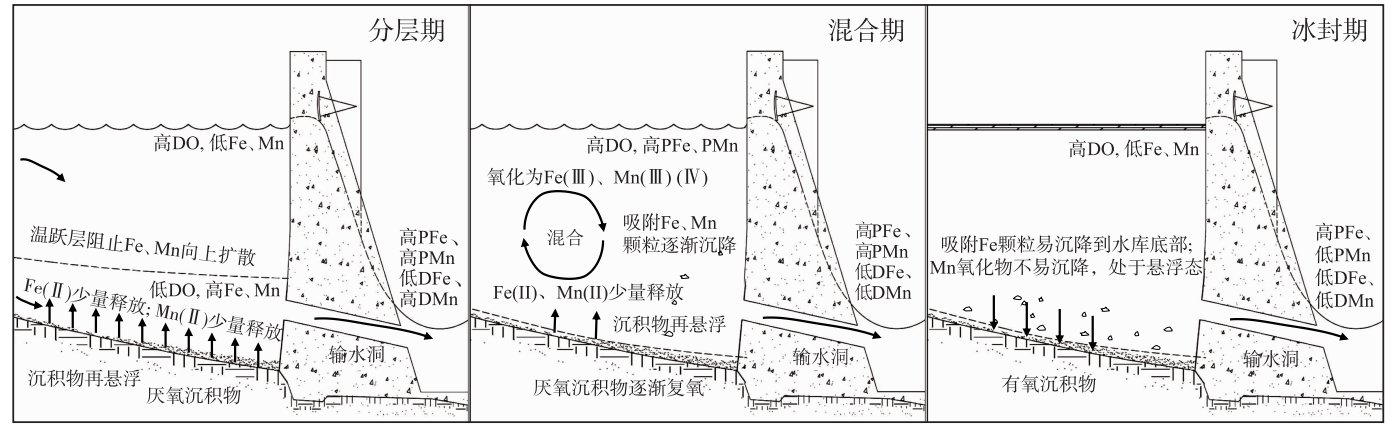

图 6 碧流河水库铁和锰的迁移对水库分层及悬浮物行为的响应规律

Fig.6 Iron and manganese mobilization in response to reservoir stratification and suspended sediment behaviors in the Biliuhe Reservoir

3.1 .2 混合期 碧流河水库在 3-5 月和 10-12 月中旬为混合期, 水库中 DO 浓度逐渐升高. 由于水库的热 分层结构失稳, 水体存在强烈的对流扩散作用, 导致水库底部的 DFe 和 DMn 能够迅速地向上输送, 同时伴 随着 $\mathrm{Fe}$ 和 $\mathrm{Mn}$ 的氧化. 由于在 $\mathrm{pH} 6 \sim 8$ 条件下 $\mathrm{Mn}$ 氧化速率缓慢, 通常还需要有锰氧化微生物的参与 ${ }^{[20,22]}$, 在混合期表层和中层的 DMn 浓度要高于其他时期, 而 $\mathrm{Fe}$ 能够被迅速氧化, 因此 DFe 能够在数小时或数天 内迅速被再氧化除去 ${ }^{[5,23]}$. 在表层颗粒沉降吸附以及 $\mathrm{Fe}$ 和 $\mathrm{Mn}$ 氧化物絮凝体的双重作用下, 悬浮物中的 $\mathrm{Fe}$ 和 Mn 含量升高 (图 5), 而且水库各层悬浮物中的 $\mathrm{Fe}$ 和 Mn 差异并不明显, 因此混合期 PFe 和 PMn 浓度要 高于其他时期.

沉积物的通常受到水动力扰动 (风浪、水流及暴风雨等)、底栖生物活动、人为干扰 (清淤、采砂、船舶行 驶等) 的影响而再次悬浮到水体中, 许多研究表明再悬浮会加剧沉积物中磷和重金属的释放 ${ }^{[24,26]}$. 水库内波 引起的温跃层的运动会导致沉积物的再悬浮 ${ }^{[27]}$, 从图 2 中可以看出, 碧流河水库在分层期 6-9 月份, 温跃 层越来越接近底部, 当温跃层越靠近底部时越容易引起沉积物的再悬浮 ${ }^{[28]}$, 由于沉积物 $\mathrm{Fe}$ 含量高于悬浮 物, 而 Mn 含量低于悬浮物, 因此沉积物的再悬浮会引起底层悬浮物中 $\mathrm{Fe} / \mathrm{Mn}$ 的增加, 可以解释几次由于沉 积物再悬浮引起的 PFe 浓度的上升, 因此 Fe 浓度受 TSS 的影响要大于 Mn. 由于分层期和混合期风浪的驱 动, 水库浅水区细颗粒的沉积物会受到扰动再悬浮到水体中, 在暴雨径流及平流输送的作用下, 到水深更深 的区域再沉积下来, 这一机制与沉积物中 Mn 的地球化学富集过程一起 ${ }^{[29]}$, 使得深水区沉积物表层 Mn 含量 显著高于浅水区 ${ }^{[30]}$. 从监测结果来看, 与 $\mathrm{Mn}$ 不同的是, 碧流河水库沉积物的再悬浮是沉积物中 $\mathrm{Fe}$ 向底层 
水体释放的主要来源, 导致了底层水体中 $\mathrm{PFe}$ 浓度的升高. 此外, 悬浮物与沉积物中 $\mathrm{Fe} / \mathrm{Mn}$ 的差异为定量分 析碧流河沉积物再悬浮的影响提供了可行的方法,在后续的研究中可以得到进一步的讨论.

如图 6 所示, 由于混合期的水力混合作用, DFe 和 DMn 进一步氧化并沉降,在沉积物颗粒再悬浮的共同 影响下, 虽然 TFe 和 TMn 的浓度较高, 但是主要以 PFe 和 PMn 为主, 由于大量的 Fe 和 Mn 氧化物絮凝体可 能会导致净水厂滤池堵塞,仍需要优化絮凝剂投放量以及调整滤池反冲洗参数等.

3.1 .3 冰封期 碧流河水库在 12 月下旬到 2 月为冰封期, 碧流河水库在冰封期 DO 浓度很高, 接近饱和溶解 度. 在有氧条件下, $\mathrm{Fe} 、 \mathrm{Mn}$ 主要以氧化物的形式存在, 因此在冰封期 DFe 和 DMn 极低. 冰封期虽然底层水体 在冰盖的阻隔下,很难受到风浪的扰动, 但是由于水库输水口持续供水, 仍能观测到底部水体的流动, 会对 水库底泥产生一些扰动, 会使得易悬浮的颗粒再次进人到水体中. 在冰封期使用水下摄像机对水下环境条 件进行观测 (图 7), 由于冰封期水温较低, 在混合期沉降的细小颗粒以及 $\mathrm{Fe} 、 \mathrm{Mn}$ 的氧化物以很慢的速度沉 降, 在水库底层以絮状的悬浮物大量存在, 短期内难以沉降到水库底部沉积物中, 因此在水库底层 PFe、PMn 仍占主要比例. 如图 7 所示, 在冰封期水深较深处 (15 m 以上) 距底部 $5 \sim 10 \mathrm{~m}$ 普遍存在大量的絮状悬浮物, 取水口位于水库底高程以上 $10 \mathrm{~m}$ 左右, 对供水水质稍有影响.

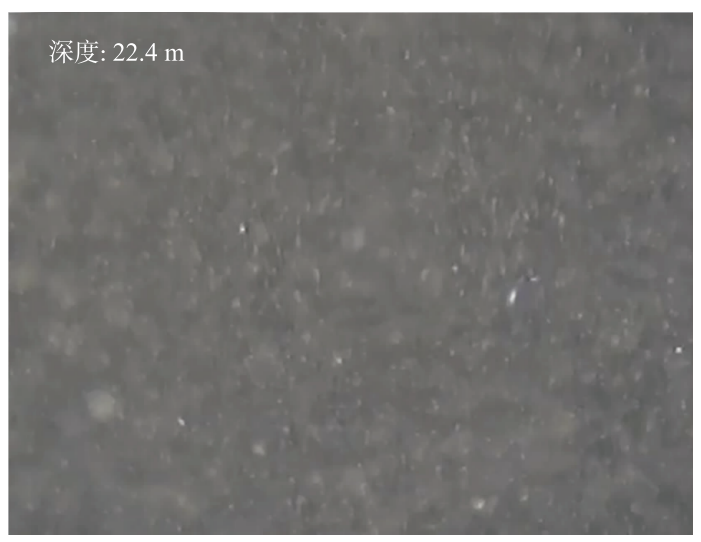

图 7 冰封期水下摄像机拍摄的碧流河水库底层悬浮物图像

Fig.7 The suspended sediment photo captured by an underwater camera in the bottom layer of the Biliuhe Reservoir with ice covered

碧流河水库季节性的分层规律影响了水库中铁和锰在水一悬浮物一沉积物之间的迁移. 根据以上监测 数据, 对碧流河水库铁和钽的迁移规律进行总结 (图 6), 可指导碧流河水库供水方案的制订, 降低因水库输 水中 $\mathrm{Fe} 、 \mathrm{Mn}$ 浓度升高而引起的饮用水供水风险. 虽然这一规律是基于碧流河水库的监测数据得到, 同样可 以为其他相似的供水水库提供参考.

\section{2 水质管理建议}

3.2.1 分层取水 水库在夏季容易发生水温分层现象, 分层取水多以控制水库下泄水温为目的 ${ }^{\left[{ }^{[31]}\right.}$. 近年来由 于水库内水质的垂向上不均匀引起的分层, 越来越多的水库采用分层取水来满足供水需求. 阿哈水库改变 下层固定取水方式为优化分层取水, 以避免底层铁锰浓度上升对城市供水的影响, 取得了良好的效果 ${ }^{[32]}$. 汤河水库为避免底层水体水质恶化对供水的影响, 对取水口结构进行改造, 采用分层取水方式向辽阳市供

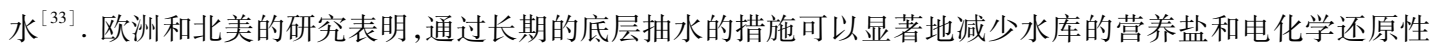
物质 ${ }^{[34]}$. 根据上述规律, 碧流河水库应当分层期从中上层取水, 由图 2 可以看出, 在 8-9 月份底层 DO 浓度 最低, $\mathrm{Fe}$ 和 $\mathrm{Mn}$ 释放的风险最大, 温跃层上界面和氧化还原界面在 $49 \sim 50 \mathrm{~m}$ 高程处, 现有输水洞底高程为 $42.5 \mathrm{~m}$, 显然容易受到影响, 应在 $50 \mathrm{~m}$ 高程以上设立取水口. 混合期容易受到沉积物释放向上传输和再悬浮 的影响, 应当从水库上层取水, 水库正常蓄水位为 $69 \mathrm{~m}$, 经统计近十年来水库月初水位在 $61 \mathrm{~m}$ 高程以上居 多, 可在 $60 \mathrm{~m}$ 左右增设取水口. 在冰封期要避免水库底层水体的大量絮凝的悬浮物, 大约在水底高程以上 
$10 \mathrm{~m}$, 可继续采用现有输水洞取水. 综上所述, 除保留现有 $42.5 \mathrm{~m}$ 输水洞外, 需增加 $50.5 \mathrm{~m}$ 和 $60.5 \mathrm{~m}$ 的取水 口,取水结构物可采用坚塔式取水口,细节方案需进一步优化.

3.2 .2 水库曝气 为削减湖泊或水库下层水体的内源污染负荷,欧美国家早在 $1980 \mathrm{~s}$ 采用曝气技术对下层水 体进行充气,用以提高 DO 浓度,改善氧化还原条件, 取得了良好的效果 ${ }^{[35]}$. 扬水曝气技术也在国内汾河水 库、金盆水库等得到应用,能够有效地减少沉积物铁和锰的释放 ${ }^{[36-37]}$. Carvins Cove 水库中深层曝气系统对 锰在水一沉积物界面释放通量的影响的研究结果表明该系统显著地减少了沉积物中锰的释放通量,在关闭 系统较长时间后底层水体的 DMn 浓度上升, 该系统可以作为供水水库水处理的前一步预处理 ${ }^{[21,38]}$. 为减少 碧流河水库沉积物中铁和锰的释放对供水的影响, 在取水口附近水域布设若干台深层曝气系统, 在分层期 开启系统可以减少 DFe 和 DMn 浓度的升高. 在水库取水口上游 S1 S2 之间深水区布设深层曝气系统可以 减少沉积物释放和再悬浮后再经径流输送对供水水质的影响.

3.2 .3 联合供水 除碧流河水库外, 大连市城市集中式供水水源地还有英那河水库、洼子店水库以及大沙河 等, 大伙房水库调水工程也已在 2014 年向碧流河水库供水. 这些水源地已通过管渠连通,形成一个协同的 供水系统. 这一系统在进行水量丰枯调节供水的基础上, 也可以考虑水质因素进行调度, 适时地切换供水水 源,避免碧流河水库 $\mathrm{Fe} 、 \mathrm{Mn}$ 浓度超标对供水产生的影响.

\section{4 结论}

1) 碧流河水库水温及 $D O$ 浓度分层的季节性特征明显, 水库的热分层以及底层缺氧是影响 $\mathrm{Fe} 、 \mathrm{Mn}$ 浓度 的重要因素. Spearman 相关分析结果表明 Fe 浓度主要受 TSS、TN 和 TP 浓度的影响, Mn 浓度主要受 TSS、 $\mathrm{DO} 、 \mathrm{pH}$ 和 TN 的影响.

2) 碧流河水库铁和锰的季节变化规律存在差异, 悬浮物行为也是影响铁锰在水一沉积物界面迁移的重 要因素. 分层期底层形成厌氧环境以及温跃层阻碍 DMn 扩散, 使得沉积物释放的 DMn 在底层累积, 而由于 碧流河水库较高浓度的 $\mathrm{NO}_{3}^{-}$存在, 沉积物中 $\mathrm{DFe}$ 的释放很少; 混合期由于水体的强烈混合, 加之 $\mathrm{Mn}$ 的氧化 速率缓慢, 导致水库上层和中层 Mn 浓度升高; 冰封期颗粒物沉降速率缓慢, 絮凝的颗粒物以及其吸附的 Mn 在水库底层长期悬浮, 难以沉降到水库底部, 导致悬浮物中 $\mathrm{Mn}$ 含量显著高于沉积物. 沉积物的再悬浮对碧 流河水库底层水体中铁的影响要更为明显, 导致了底层水体 PFe 浓度的升高, 因此 TSS 对 Fe 浓度的影响要 比对 Mn 的影响大.

3) 建议应在碧流河水库采用一些原位水质管理措施, 比如分层取水、水库曝气以及联合供水等, 以减少 铁和锰的浓度升高对供水产生的影响,保障大连市城市供水安全.

致谢: 感谢碧流河水库管理局在船上和冰上采样及样品分析过程中提供的设备与人力支持.

\section{5 参考文献}

[ 1 ] Sommerfeld EO ed. Iron and manganese removal handbook. Denver, Colorado: American Water Works Association, 1999: 4-5.

[ 2 ] Frisbie SH, Mitchell EJ, Dustin H et al. World Health Organization discontinues its drinking-water guideline for manganese. Environ Health Perspect, 2012, 120(6) : 775-778. DOI: 10.1289/ehp.1104693.

[ 3 ] Kenari SLD, Barbeau B. Integratedpyrolucite fluidized bed-membrane hybrid process for improved iron and manganese control in drinking water. Water Res, 2017, 113: 50-61. DOI: 10.1016/j.watres.2017.01.053.

[ 4 ] Gerke TL, Little BJ, Barry MJ. Manganese deposition in drinking water distribution systems. Sci of the Total Environ, 2016, 541: 184-193. DOI: 10.1016/j.scitotenv.2015.09.054.

[ 5 ] Davison W. Iron and manganese in lakes. Earth-Sci Rev, 1993, 34(2): 119-163. DOI: 10. 1016/0012-8252 (93) 90029-7.

[ 6 ] Abesser C, Robinson R. Mobilisation of iron and manganese from sediments of a Scottish Upland Reservoir. J Limnol, 2010, 69(1) : 42-53. DOI: 10.3274/JL10-69-1-04.

[ 7 ] Zaw M, Chiswell B. Iron and manganese dynamics in lake water. Water Res, 1999, 33( 8) : 1910-1990. DOI: 10.1016/ S0043-1354( 98 ) 00360-1. 
[ 8 ] Betancourt C, Jorge F, Suarez R et al. Manganese sources and cycling in a tropical eutrophic water supply reservoir, Paso Bonito Reservoir, Cuba. Lake Reserv Manage, 2010, 26(3) : 217-226. DOI: 10.1080/07438141.2010.519856.

[ 9 ] Xu YR, Xu ZJ, Xu W et al. Characteristics of Fe, Mn vertical distribution in a thermal stratified reservoir. J Lake Sci, 1999, 11(2): 117-122. DOI: 10.18307/1999.0205. [徐毓荣, 徐钟际, 徐玮等. 水温分层型水库铁、锰垂直分布特 征. 湖泊科学, 1999, 11(2): 117-122.]

[10] Peng H, Zheng XL, Chen L et al. Analysis of numerical simulations and influencing factors of seasonal manganese pollution in reservoirs. Environ Sci Pollut R, 2016, 23(14) : 14362-14372. DOI: 10.1007/s11356-016-6380-3.

[11] Liu SY, Zheng C, Yuan Q et al. Analysis on the variation characteristics of iron and manganese concentration and its genesis in Changtan Reservoir in Taizhou, Zhejiang Province. Environmental Science, 2014, 35(10) : 3702-3708. DOI: 10. 13227/j.hjkx.2014.10.009. [刘树元, 郑晨, 袁琪等. 台州长潭水库铁锰质量浓度变化特征及其成因分析. 环境科 学, 2014, 35(10): 3702-3708.]

[12] Yang SY, Zhao J, Yu HZ et al. Vertical distribution characteristics of Fe and Mn in subtropical reservoirs during summer. Environmental Science, 2017, 38(11) : 4546-4552. DOI: 10.13227/j.hjkx.201704233. [杨思远, 赵剑, 余华章等. 南 亚热带地区水库夏季铁、锰垂直分布特征. 环境科学, 2017, 38(11) : 4546-4552.]

[13] Galvez JA, Niell FX. Sedimentresuspension in a monomictic eutrophic reservoir. Hydrobiologia , 1992, 235( 1) : 133-141. DOI: $10.1007 / \mathrm{BF} 00026206$.

[14] Ji XC, Wang SR, Jiang X. Preliminary study of the three-dimension model of the lake water-sediment interface. Research of Environmental Sciences, 2004, 17(S1) : 1-5. [金相灿, 王圣瑞, 姜霞. 湖泊水-沉积物界面三相结构模式的初步研 究. 环境科学研究, 2004, 17(S1) : 1-5.]

[15] Chen Y, Gao G, Li YP et al. Hydrostatic setting of suspended matter of Lake Taihu. J Lake Sci, 2006, 18( 5) : 528-534. DOI : $10.18307 / 2006.0515$. [ 陈均, 高光, 李一平等. 太湖水体中悬浮物的静沉降特征. 湖泊科学, 2006, 18(5): 528-534.]

[16] Davison W. Supply of iron and manganese to an anoxic lake basin. Nature, 1981, 290 (5803) : 241-243. DOI: 10. 1038/290241a0.

[17] Wetzel RG. Limnology: lake and river ecosystems: 3rd edition. San Diego: Academic Press, 2001: 291.

[18] Sholkovitz ER, Copland D. The chemistry of suspended matter in Esthwaite Water, a biologically productive lake with seasonally anoxic hypolimnion. Geochim Cosmochim Ac, 1982, 46(3) : 393-410. DOI : 10.1016/0016-7037(82)90231-9.

[19] Imberger J, Patterson JC. Physical limnology. Adv Appl Mech, 1989, 27: 303-475. DOI: 10. 1016/S0065-2156 ( 08) 70199-6.

[20] Martynova MV. Exchange of Mn compounds between bottom sediments and water: 1. Mn flux from water to the bed. Water Resour, 2013, 40(6) : 640-648. DOI: 10.1134/S0097807813060079.

[21] Gantzer PA, Bryant LD, Little JC. Controlling soluble iron and manganese in a water-supply reservoir using hypolimnetic oxygenation. Water Res, 2009, 43(5) : 1285-1294. DOI: 10.1016/j.watres.2008.12.019.

[22] Munger ZW, Carey CC, Gerling AB et al. Effectiveness of hypolimnetic oxygenation for preventing accumulation of Fe and Mn in a drinking water reservoir. Water Res, 2016, 106: 1-14. DOI: 10.1016/j.watres.2016.09.038.

[23] Munger ZW, Shahady TD, Schreiber ME. Effects of reservoir stratification and watershed hydrology on manganese and iron in a dam-regulated river. Hydrol Process, 2017, 31(8) : 1622-1635. DOI: 10.1002/hyp.11131.

[24] Yu S, Li HB. Perspectives on the release of heavy metals via sediment resuspension. Ecology and Environmental Sciences, 2010, 19(7): 1724-1731. [俞慎, 历红波. 沉积物再悬浮-重金属释放机制研究进展. 生态环境学报, 2010,19 (7) : 1724-1731.]

[25] Zheng XL, Zhang JJ, Chen L. Advances in the study of migration and transformation mechanisms of endogenous phosphorus via sediment resuspension. Advances in Water Science, 2013, 24(2) : 287-295. [郑西来, 张俊杰, 陈蕾. 再悬浮条件 下沉积物内源磷迁移-转化机制研究进展. 水科学进展, 2013, 24(2): 287-295.]

[26] Simpson SL, Apte SC, Batley GE. Effect ofshort term resuspension events on trace metal speciation in polluted anoxic sediments. Environ Sci Technol, 1998, 32(5) : 620-625. DOI: 10.1021/es970568g.

[27] Imboden DM, Wüest A. Mixing mechanisms in lakes. In: Lerman A, Imboden DM, Gat J et al eds. Physics and chemistry of lakes. Berlin, Heidelberg: Springer, 1995: 83-138.

[28] Pierson DC, Weyhenmeyer GA. High resolution measurements of sediment resuspension above an accumulation bottom in a 
stratified lake. Hydrobiologia, 1994, 284( 1) : 43-57. DOI: 10.1007/BF00005730.

[29] Schaller T, Wehrli B. Geochemical-focusing of manganese in lake sediments-An indicator of deep-water oxygen conditions. Aquat Geochem, 1997, 2(4) : 359-378. DOI: 10.1007/BF00115977.

[30] Zhu L, Liu JW, Xu SG et al. Deposition behavior, risk assessment and source identification of heavy metals in reservoir sediments of Northeast China. Ecotox Environ Safe, 2017, 142: 454-463. DOI: 10.1016/j.ecoenv.2017.04.039.

[31] Du XH, Yu WQ, Rui JL. Hydropower ecology practice-selective withdrawal structures. Water Power, 2008, 34(12) : 2832. [杜效鹄, 喻卫奇, 芮建良. 水电生态实践一一分层取水结构. 水力发电, 2008, 34(12): 28-32.]

[32] Xu YR, Xu ZJ, Xiang S et al. Vertical distribution of Fe and Mn and optimal pumping depth in a seasonal oxygen shortage reservoir. Acta Scientiae Circumstantiae, 1999, 19(2) : 37-42. [徐毓荣, 徐钟际, 向申等. 季节性缺氧水库铁、锰垂直 分布规律及优化分层取水研究. 环境科学学报, 1999, 19(2): 37-42.]

[33] Cao GF, Li Q. Introduction to the reconstruction of multi-level intake structures in the Tanghe Reservoir. Water Resources \& Hydropower of Northeast China, 2015, 33(9): 4-5. [曹桂芬, 李琦. 汤河水库分层取水改造工程简述. 东北水利水 电, $2015,33(9): 4-5$. ]

[34] Nurnberg GK. Lake responses to long-term hypolimnetic withdrawal treatments. Lake Reserv Manage, 2007, 23(4) : 388409. DOI: 10.1080/07438140709354026.

[35] Beutel MW, Horne AJ. A review of the effects of hypolimnetic oxygenation on lake and reservoir water quality. Lake Reserv Manage, 1999, 15(4) : 285-297. DOI: 10.1080/07438149909354124.

[36] Huang TL, Li JJ. Water lifting and aeration technology for improving raw water quality in Fenhe River Reservoir. Water Technology, 2007, 1(4) : 13-16. [黄廷林, 李建军. 扬水曝气技术对汾河水库原水水质的改善. 供水技术, 2007, 1 (4) : 13-16.]

[37] Zhou ZZ, Huang TL, Li Y et al. Improvement of water quality and sediment control by WLAs in a source water reservoir. China Environmental Science, 2017, 37(1): 210-217. [周子振, 黄廷林, 李扬等. 扬水曝气器对水源水库水质改善 及沉积物控制. 中国环境科学, 2017, 37(1): 210-217.]

[38 ] Bryant LD, Hsu-Kim H, Gantzer PA et al. Solving the problem at the source: Controlling Mn release at the sediment-water interface via hypolimnetic oxygenation. Water Res, 2011, 45(19) : 6381-6392. DOI: 10.1016/j.watres.2011.09.030. 